Scientia Agricola

http://dx.doi.org/10.1590/0103-9016-2015-0214

\title{
Humic substances and its distribution in coffee crop under cover crops and weed control methods
}

\author{
Bruno Henrique Martins ${ }^{1}$, Cezar Francisco Araujo-Junior ${ }^{1 *}$, Mario Miyazawa ${ }^{1}$, Karen Mayara Vieira ${ }^{1,2}$
}

${ }^{1}$ Agronomic Institute of Paraná, Rod. Celso Garcia Cid, km 375 - 86047-902 - Londrina, PR - Brazil.

${ }^{2}$ North University of Paraná - Dept. of Chemistry, Rua

Marselha, 183 - 86041-140 - Londrina, PR - Brazil.

*Corresponding author <cezar_araujo@iapar.br>

Edited by: Carlos Eduardo Pellegrino Cerri

\begin{abstract}
Humic substances (HS) comprise the passive element in soil organic matter (SOM), and represent one of the soil carbon pools which may be altered by different cover crops and weed control methods. This study aimed to assess HS distribution and characteristics in an experimental coffee crop area subjected to cover crops and cultural, mechanical, and chemical weed control. The study was carried out at Londrina, in the state of Paraná, southern Brazil $\left(23^{\circ} 21^{\prime} 30^{\prime \prime}\right.$ S; $51^{\circ} 10^{\prime} 17^{\prime \prime}$ W). In 2008 , seven weed control/cover crops were established in a randomized block design between two coffee rows as the main-plot factor per plot and soil sampling depths $(0-10 \mathrm{~cm}, 10-20 \mathrm{~cm}, 20-30 \mathrm{~cm}$ and $30-40 \mathrm{~cm})$ as a split-plot. HS were extracted through alkaline and acid solutions and analyzed by chromic acid wet oxidation and UV-Vis spectroscopy. Chemical attributes presented variations in the topsoil between the field conditions analyzed. Cover crop cutting and coffee tree pruning residues left on the soil surface may have interfered in nutrient cycling and the humification process. Data showed that humic substances comprised about $50 \%$ of SOM. Although different cover crops and weed control methods did not alter humic and fulvic acid carbon content, a possible incidence of condensed aromatic structures at depth increments in fulvic acids was observed, leading to an average decrease of $53 \%$ in the $E_{4} / E_{6}$ ratio. Humin carbon content increased $25 \%$ in the topsoil, particularly under crop weed-control methods, probably due to high incorporation of recalcitrant structures from coffee tree pruning residues and cover crops.

Keywords: UV-Vis spectroscopy, conservation agriculture, soil organic matter, carbon content, chemical fractionating
\end{abstract}

Ultraviolet and visible (UV-Vis) spectroscopy have

\section{Introduction}

Coffee is one of the most important crops in Brazilian agribusiness. A number of management systems in coffee crops have shown potential for improving soil organic matter (SOM) content (Pavan et al., 1999; AraujoJunior et al., 2013; Martins et al., 2015).

Sustainability of a production system is directly affected by different land uses and management. Soil use practices and management must provide benefits in terms of crop yield, weed suppression/control, and also SOM carbon content (Cardoso et al., 2013).

Given the crucial role SOM plays in soil fertility, by affecting chemical, physical and biological properties, it has been widely used as a soil quality evaluation parameter. Also, several studies have shown the potential for SOM humified fraction as a tool for assessing soil history characteristics (management, turnover, origin material and anthropomorphic action impact) (Canellas et al., 2004).

Humic substances (HS) are considered one of the main organic carbon pools in soil (Song et al., 2014), comprising nearly $75 \%$ of SOM (Santos et al., 2010), and are separated accordingly to their solubility at different $\mathrm{pH}$ levels, into humic acid (HA), fulvic acid (FA) and humin (HU) (Stevenson, 1994). Changes in HS features (such as composition, distribution and carbon content) have been widely used and reported in the literature as parameters for the evaluation of agricultural management systems (Canellas et al., 2010). been widely used in HS structural investigations. The UV-Vis spectroscopy comprises an analytical technique that allows for condensation assessment, and consequent humification degree evaluation (Fuentes et al., 2006).

The $\mathrm{E}_{4} / \mathrm{E}_{6}$ ratio (ratio between the absorbance intensity at 465 and $665 \mathrm{~nm}$ ) is a classic index widely used in UV-Vis spectroscopy to evaluate HS structural features (condensation/humification degree) (Chen et al., 1977; Helal et al., 2011).

Carbon content distribution in SOM humic fractions in coffee crops subjected to different weed control methods and cover crops is a matter for research. This study aimed to assess HS carbon content distribution and the condensation/humification degree in a long-term trial coffee plantation area subjected to weed control and cover crop managements.

\section{Materials and Methods}

\section{Experimental Field}

The experimental field was located at Londrina, in the state of Paraná, southern Brazil (2321'30" S; $51^{\circ} 10^{\prime} 17^{\prime \prime}$ W). The trial soil was a Typic Haplorthox (Dystroferic Red Latosol) with very clayey texture, 80 dag $\mathrm{kg}^{-1}$ of clay at 0-40 cm layer (Araujo-Junior et al., 2013). More details about soil characterization and mineralogical composition of this soil are given by Castro Filho and Logan (1991). 
Coffee trees (Coffea arabica L.), at the cultivar Mundo Novo IAC 379-19, were planted in 1978, with $3.50 \mathrm{~m}$ row spacing $\times 2.00 \mathrm{~m}$ spacing between coffee pits with two plants per pit. In 2008, the experiment was installed in a randomized block design with four replicates, comprising a split-plot scheme with weed control and cover crops between coffee rows, the main plot factor, with four sampling depths $(0-10 \mathrm{~cm} ; 10-20 \mathrm{~cm} ; 20$ $30 \mathrm{~cm} ; 30-40 \mathrm{~cm}$ ) in the split-plot.

Seven different weed control / cover crop were considered: (i) hand weeding - HAWE; (ii) portable mechanical mower - PMOW; (iii) pre (oxyfluorfen, $240 \mathrm{~g}$ $\mathrm{L}^{-1}$ ) and post (glyphosate, $360 \mathrm{~g} \mathrm{~L}^{-1}$ ) emergence herbicide - HERB; (iv) peanut horse (Arachis hypogeae) cover crop - GMAY; (v) dwarf mucuna (Mucuna deeringiana) cover crop - GMMA; (vi) no-weed control between coffee rows - SCAP; (vii) weed check - CONT (no-weed control between coffee rows and below canopy). In each inter-row of the coffee crop, two rows of the cover crops were sowed at a row spacing of $0.5 \mathrm{~m}$ and $0.25 \mathrm{~m}$ between pits. Cover crops were cut off in Mar, 2014.

In September 2013, coffee tree pruning was carried out by cutting off all plagiotropic branches at 20-30 $\mathrm{cm}$ from the orthotropic branch ("esqueletamento") and by cutting off the orthotropic branch at $1.60 \mathrm{~m}$ above ground ("decote"). The pruning residues were mowed and left on the soil surface to allow biological incorporation. Further details regarding trial and site conditions are given by Araujo-Junior et al. (2013).

\section{Soil Sampling}

Soil samples were collected in March, 2014, from the center of the inter-rows, about $1.75 \mathrm{~m}$ from the coffee tree stems, using a traditional mattock at the four above- mentioned depth increments. Samples were stored in plastic bags, air dried at room temperature, sieved through a $2.0-\mathrm{mm}$ mesh and mechanically ground on a knife-mill. After the pre-treatment, samples were reserved for further humic substance extraction.

Chemical analysis for bulk soil samples for $\mathrm{pH}_{\text {, }}$ available phosphorus, and exchangeable calcium, magnesium and potassium assessment were carried out in accordance with procedures described in Pavan et al. (1992).

\section{Humic Substance Extraction}

Humic substances were separated in accordance with the methodology proposed by Benites et al. (2003). Briefly, the method consisted of extraction with $\mathrm{NaOH}$ $0.1 \mathrm{~mol} \mathrm{~L}^{-1}$, at a sample:solvent ratio of $1: 10$. After centrifugation processes, HA and FA (supernatant) and HU (precipitate) were separated. Given the difference in solubility according to $\mathrm{pH}$ levels, the supernatant was separated by adding $\mathrm{H}_{2} \mathrm{SO}_{4} 20 \%$ until a $\mathrm{pH}$ of 1.0 was reached. The precipitated $\mathrm{HA}$ was vacuum filtered at $0.45 \mu \mathrm{m}$ membrane and redissolved with $\mathrm{NaOH} 0.1 \mathrm{~mol}$ $\mathrm{L}^{-1}$ in a $50 \mathrm{~mL}$ volumetric flask. The filtered FA was also collected in a $50 \mathrm{~mL}$ volumetric flask. The fractions obtained were reserved for further analysis.

\section{Humic Fraction Carbon Content}

Carbon content determination for humic fractions was carried out in accordance with a modified WalkleyBlack method (Walkley and Black, 1934) as proposed by Benites et al. (2003). To compare and validate the results from HA and FA, and HU fractions, the carbon content was also calculated in accordance with Schulte and Hoskins, 2011.

\section{UV-Vis Spectroscopy}

UV-Vis spectroscopy measurements were carried out in a Genesys 10UV spectrometer, scanning a range of 200 to $1100 \mathrm{~nm}$, with $1.0 \mathrm{~nm}$ spectral resolution. HA and FA solutions in a $200-400 \mathrm{mg} \mathrm{L}^{-1}$ concentration were diluted to $10 \mathrm{~mL}$ by adding $0.05 \mathrm{~mol} \mathrm{~L}^{-1} \mathrm{NaHCO}_{3^{\prime}}$ and the $\mathrm{pH}$ was adjusted to 8.0. The $\mathrm{E}_{4} / \mathrm{E}_{6}$ ratios were obtained by the quotient between absorbance intensities at 465 and $665 \mathrm{~nm}$ (Chen et al., 1977).

\section{Data Analysis}

All the data were statistically analyzed using Origin Pro 8.0 software, by split-plot Analysis of Variance (ANOVA) by depth increments, with a significance level of $p<0.05$.

\section{Results and Discussion}

\section{Chemical Analysis}

The chemical attributes for topsoil layers $10-10 \mathrm{~cm}$ and $10-20 \mathrm{~cm}$ ) from the Red Dystroferic Red Latosol subjected to different weed control methods between coffee crop rows are presented in Figure 1. Results from the following depth increments $(20-30 \mathrm{~cm}$ and $30-40 \mathrm{~cm})$ were not shown, since no alterations in chemical attributes for the weed control methods considered were observed.

The weed control methods between coffee rows affected the values of soil $\mathrm{pH}$ and exchangeable $\mathrm{Ca}$ and $\mathrm{Mg}$ in the topsoil $(0-10 \mathrm{~cm})$. However, no alterations were observed for the levels of available $\mathrm{P}$ and exchangeable K (Figure 1).

Results may be attributed to a higher incidence of exchangeable $\mathrm{Ca}$ and $\mathrm{Mg}$ complexed with soil organic matter and fresh plant input in the superficial layers.

Higher values of $\mathrm{pH}$ observed for SCAP and CONT areas (both presenting similar field characteristics with no disturbance inter-row) may also be related to the effects of soil surface coverage by weed plants and coffee tree residues from pruning.

Probably the organic matter mineralization process led to a high incidence of carboxylic groups (COO-), which bonds to free $\mathrm{H}^{+}$from soil solution, leading to increased $\mathrm{pH}$ in areas under SCAP and CONT weed control management methods, compared to the HERB one.

Coffee pruning, residue mowing and distribution over the inter-row soil surface may have increased complexation in the topsoil, and probably led to nutrient homogenization along depth increments, causing no variations at deeper layers. 

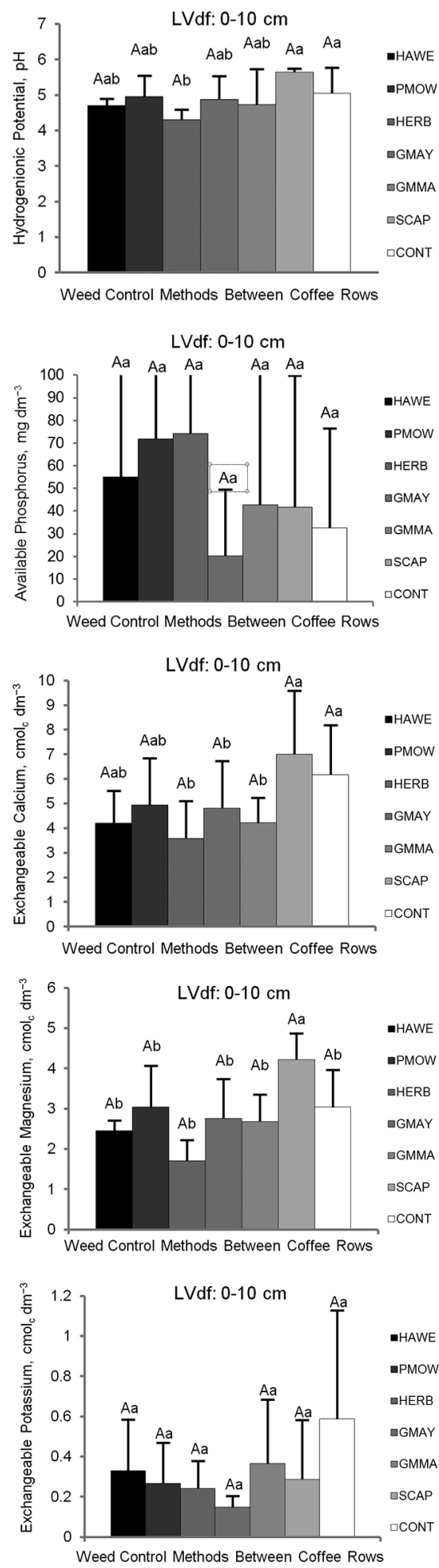
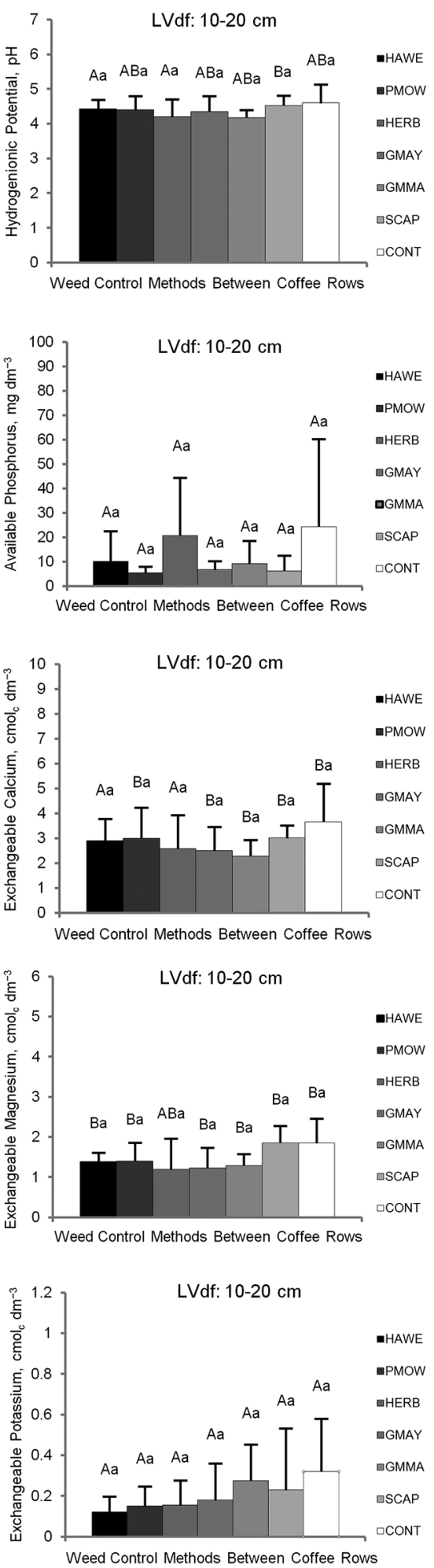

Figure 1 - Chemical properties of a Dystropherric Red Latosol - LVdf in coffee crop submitted to cover crops and weed control methods between coffee rows in two depths. HAWE: hand weeding; PMOW: portable mechanical mower; HERB: pre and post-emergence herbicides; GMAY: soil cover with green manure peanut horse (Arachis hypogeae); GMMA: soil cover with green manure dwarf mucuna; SCAP: no-weed control between coffee row; CONT: weed check. The upper case letters above bars mean statistical analysis along depth increments within a given weed control/cover crop system. Lower case letters inside bars means statistical analysis between weed control/cover crop at given depth increment layer (Tukey test, alpha $=0.05$ ). Vertical bars are the standard error. 


\section{Humic Carbon Distribution}

Figure 2 shows the HS carbon percentage related to bulk soil organic carbon. HS carbon comprised between 47 $\%$ and $51 \%$ of the bulk soil organic carbon content. Based on the results shown in Figure 2, cover crops and weed control methods presented overall similar behavior with increases in the HS carbon percentage at depth increments.

It is difficult to recommend absolute soil carbon content value as a standard, as well as the carbon concentration for humic fraction. Carbon content may vary depending on soil tillage system, cover crop or cropping rotation. Stable organic matter (HS) comprises $60 \%$ to $80 \%$ of SOM composition (Bot and Benites, 2005).

Differences between the bulk soil carbon content and the humic fraction carbon content observed may be attributed to the SOM non-humic fraction. SOM non-humic fraction comprises carbohydrates, soil lipids, amino acids, proteins, lignin, nucleic acids, organic acids, particulate organic matter, and also living organic matter (soil microfauna) (Bot and Benites, 2005). For instance, carbohydrates by themselves comprise about $5 \%$ to 25 $\%$ of organic matter in most soils, representing a significant soil organic carbon pool (Martín et al., 2009; Ratnayake et al., 2013).

\section{Humic (C-HA) and Fulvic (C-FA) Acids Carbon Content}

Carbon content determined from the humic substance extracts are shown in Table 1.

Cover crops and weed control methods used between coffee rows did not alter humic and fulvic acids carbon content (C-HA and C-FA, respectively) in the superficial layers $(0-10 \mathrm{~cm}$ and $10-20 \mathrm{~cm})$ (Table 2). On the other hand, the chemical weed control method (HERB) promoted C-HA decreases at 30-40 cm, while among the cultural control group, the GMMA was used as a weed control method on the coffee crop inter-row leading to C-HA decreases at $20-30 \mathrm{~cm}$.

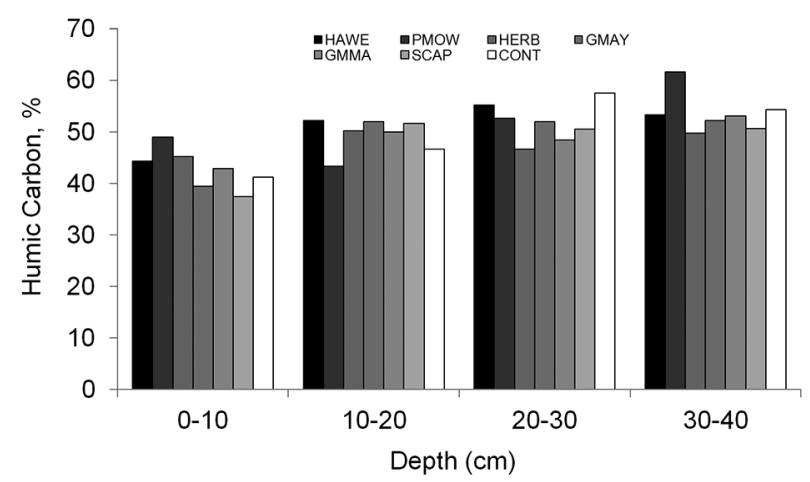

Figure 2 - Distribution of humic substances carbon under seven weed control methods in four depths between coffee rows. HAWE: hand weeding; PMOW: portable mechanical mower; HERB: pre and post-emergence herbicides; GMAY: soil cover with green manure peanut horse (Arachis hypogeae); GMMA: soil cover with green manure dwarf mucuna; SCAP: no-weed control between coffee row; CONT: weed check.
In this coffee crop area, humification processes are more advanced at deeper layers (Martins et al., 2015), leading to a higher incidence of aromatic compounds (recalcitrant polycondensed rings). However, the application of pesticides tends to alter such processes, by sorption of dissolved organic matter (Ding et al., 2002), directly affecting carbon content and distribution in SOM fractions, as observed in the HERB samples.

Data from GMMA samples may be attributable to possible microbial activity at the root zone, altering the humification process, and consequently, C-HA. In a previous study, at Miraselva, in the north of the state of Paraná, in a very clayey Dystropheric Red Latosol under the coffee crop cultivar Catuaí, it was noted that the use of leguminous species between coffee rows influenced microbial activity in rows and between rows in coffee plantations (Balota and Chaves, 2010).

HS presents a different humification degree status (FA at early stages, and HA at intermediary stages). FA presented smaller molecular weight, - allowing it to remain in soil solution for longer periods, even under adverse conditions (pH and salt concentration) (Zhang et al., 2010).

The pruning process carried out in September, 2013, with plagiotropic and orthotropic branches mowing at coffee crop inter-rows, may have contributed to the C-FA homogenization, avoiding differences between depth increments under any cover crop/weed control method analyzed, ultimately leading to the lack of variation observed for this HS.

\section{Humin Carbon Content (C-HU)}

Figure 3 shows the humin carbon content (C-HU) results. Data showed differences $(p<0.05)$ in the topsoil

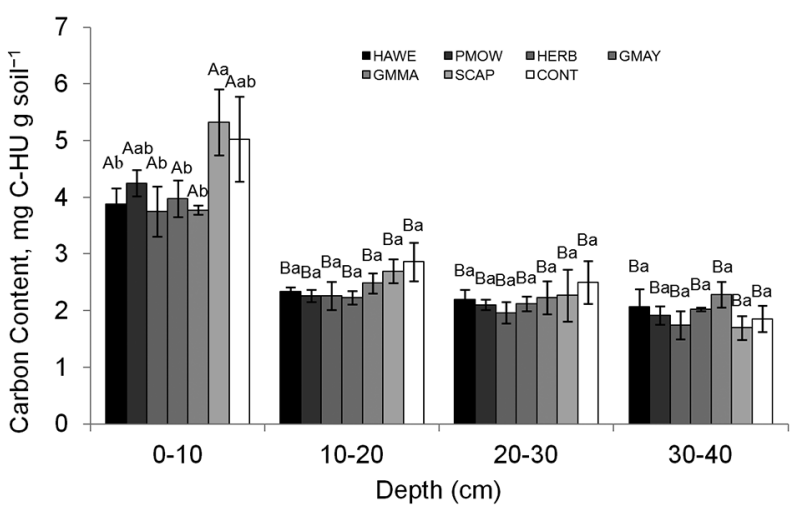

Figure 3 - Humin (HU) carbon content under seven weed control methods in four depths between coffee rows. HAWE: hand weeding; PMOW: portable mechanical mower; HERB: pre and postemergence herbicides; GMAY: soil cover with green manure peanut horse (Arachis hypogeae); GMMA: soil cover with green manure dwarf mucuna; SCAP: no-weed control between coffee row; CONT: weed check. Upper case letters mean statistical analysis along depth increments within a weed control/cover crop system. Lower case letters mean statistical analysis between weed control/cover crop at given depth increment (Tukey test, alpha $=0.05$ ) . 
Table 1 - Humic and fulvic acid carbon content under seven weed control methods in four depths between coffee rows.

\begin{tabular}{|c|c|c|c|c|c|c|c|}
\hline \multicolumn{8}{|c|}{ Weed control methods between coffee rows } \\
\hline Depth, cm & HAWE $^{1}$ & PMOW & HERB & GMAY & GMMA & SCAP & CONT \\
\hline & \multicolumn{7}{|c|}{${ }^{2}$ Humic acid carbon content, mg g soil-1 } \\
\hline $0-10$ & $2.64 \mathrm{Aa}^{\dagger}(0.04)$ & $2.36 \mathrm{Aa}^{\dagger}(0.09)$ & $2.56 \mathrm{ABa}+(0.10)$ & $2.21 \mathrm{Aa}^{\dagger}(0.24)$ & $2.41 \mathrm{Aa}^{\dagger}(0.23)$ & $2.50 \mathrm{Aa}^{\dagger}(0.14)$ & $2.63 \mathrm{Aa}^{\dagger}(0.12)$ \\
\hline $10-20$ & $2.09 \mathrm{Aa}^{\dagger}(0.27)$ & $1.94 \mathrm{Aa}^{\dagger}(0.19)$ & 2.26 Aa† (0.19) & $2.22 \mathrm{Aa}^{\dagger}(0.18)$ & $2.24 \mathrm{ABa}^{\dagger}(0.11)$ & $2.27 \mathrm{Aa}^{\dagger}(0.01)$ & $2.31 \mathrm{Aa}^{\dagger}(0.10)$ \\
\hline $20-30$ & $2.19 \mathrm{Aa}^{\dagger}(0.15)$ & $1.88 \mathrm{Aa}^{\dagger}(0.28)$ & 2.06 Aa† (0.14) & $2.11 \mathrm{Aa}^{\dagger}(0.15)$ & 1.69 $\mathrm{Bab}^{\dagger}(0.42)$ & $2.20 \mathrm{Aa}^{\dagger}(0.15)$ & $2.45 \mathrm{Ab}^{\dagger}(0.21)$ \\
\hline \multirow[t]{2}{*}{$30-40$} & $2.01 \mathrm{Aa}^{\dagger}(0.17)$ & $2.08 \mathrm{Aa}^{\dagger}(0.14)$ & $1.88 \mathrm{Ba}+(0.20)$ & $2.03 \mathrm{Aa}^{\dagger}(0.21)$ & $2.38 \mathrm{Aa}^{\dagger}(0.25)$ & $2.10 \mathrm{Aa}^{\dagger}(0.11)$ & $2.23 \mathrm{Aa}^{\dagger}(0.09)$ \\
\hline & \multicolumn{7}{|c|}{${ }^{3}$ Humic acid carbon content, $\mathrm{mg}$ g soil ${ }^{-1}$} \\
\hline $0-10$ & $2.67 \mathrm{Aa}^{\dagger}(0.06)$ & $2.40 \mathrm{Aa}^{\dagger}(0.11)$ & $2.60 \mathrm{ABa}^{\dagger}(0.10)$ & $2.24 \mathrm{Aa}^{\dagger}(0.26)$ & $2.44 \mathrm{Aa}^{\dagger}(0.25)$ & $2.53 \mathrm{Aa}^{\dagger}(0.15)$ & $2.66 \mathrm{Aa}^{\dagger}(0.14)$ \\
\hline $10-20$ & $2.12 \mathrm{Aa}^{\dagger}(0.28)$ & $1.97 \mathrm{Aa}^{\dagger}(0.21)$ & $2.30 \mathrm{Aa}^{\dagger}(0.22)$ & $2.26 \mathrm{Aa}^{\dagger}(0.21)$ & $2.27 \mathrm{ABa}^{\dagger}(0.12)$ & $2.30 \mathrm{Aa}^{\dagger}(0.02)$ & $2.34 \mathrm{Aa}^{\dagger}(0.10)$ \\
\hline $20-30$ & $2.23 \mathrm{Aa}^{\dagger}(0.17)$ & $1.91 \mathrm{Aa}^{\dagger}(0.30)$ & $2.09 \mathrm{Aa}^{\dagger}(0.16)$ & $2.13 \mathrm{Aa}^{\dagger}(0.15)$ & $1.73 \mathrm{Bab}^{\dagger}(0.44)$ & $2.22 \mathrm{Aa}^{\dagger}(0.14)$ & $2.48 \mathrm{Ab}^{\dagger}(0.20)$ \\
\hline \multirow[t]{2}{*}{$30-40$} & $2.04 \mathrm{Aa}^{\dagger}(0.19)$ & $2.11 \mathrm{Aa}^{\dagger}(0.15)$ & $1.90 \mathrm{Ba}^{\dagger}(0.21)$ & $2.06 \mathrm{Aa}^{\dagger}(0.23)$ & $2.42 \mathrm{Aa}^{\dagger}(0.27)$ & $2.13 \mathrm{Aa}^{\dagger}(0.12)$ & $2.26 \mathrm{Aa}^{\dagger}(0.08)$ \\
\hline & \multicolumn{7}{|c|}{${ }^{2}$ Fulvic acid carbon content, $\mathrm{mg} g$ soil ${ }^{-1}$} \\
\hline $0-10$ & $1.85 \mathrm{Aa}^{\dagger}(0.34)$ & $2.04 \mathrm{Aa}^{\dagger}(0.35)$ & $1.86 \mathrm{Aa}^{\dagger}(0.32)$ & $1.42 \mathrm{Aa}^{\dagger}(0.51)$ & $1.82 \mathrm{Aa}^{\dagger}(0.26)$ & $1.38 \mathrm{Aa}^{\dagger}(0.11)$ & $2.07 \mathrm{Aa}^{\dagger}(0.36)$ \\
\hline $10-20$ & $1.78 \mathrm{Aa}^{\dagger}(0.26)$ & $1.33 \mathrm{Aa}^{\dagger}(0.30)$ & $1.74 \mathrm{Aa}^{\dagger}(0.36)$ & $1.86 \mathrm{Aa}^{\dagger}(0.22)$ & $1.71 \mathrm{Aa}^{\dagger}(0.25)$ & $1.88 \mathrm{Aa}^{\dagger}(0.31)$ & $1.53 \mathrm{Aa}^{\dagger}(0.30)$ \\
\hline $20-30$ & $1.86 \mathrm{Aa}^{\dagger}(0.44)$ & $1.62 \mathrm{Aa}^{\dagger}(0.20)$ & $1.45 \mathrm{Aa}^{\dagger}(0.34)$ & $1.57 \mathrm{Aa}^{\dagger}(0.28)$ & $1.70 \mathrm{Aa}^{\dagger}(0.34)$ & $1.57 \mathrm{Aa}^{\dagger}(0.17)$ & $1.94 \mathrm{Aa}^{\dagger}(0.30)$ \\
\hline \multirow[t]{2}{*}{$30-40$} & $1.64 \mathrm{Aa}^{\dagger}(0.34)$ & $1.75 \mathrm{Aa}^{\dagger}(0.27)$ & $1.24 \mathrm{Aa}^{\dagger}(0.19)$ & $1.25 \mathrm{Aa}^{\dagger}(0.29)$ & $1.70 \mathrm{Aa}^{\dagger}(0.28)$ & $1.19 \mathrm{Aa}^{\dagger}(0.08)$ & $1.65 \mathrm{Aa}^{\dagger}(0.40)$ \\
\hline & \multicolumn{7}{|c|}{${ }^{3}$ Fulvic acid carbon content, $\mathrm{mg} g$ soil $^{-1}$} \\
\hline $0-10$ & $1.90 \mathrm{Aa}^{\dagger}(0.32)$ & $2.10 \mathrm{Aa}^{\dagger}(0.33)$ & $1.92 \mathrm{Aa}^{\dagger}(0.30)$ & $1.47 \mathrm{Aa}^{\dagger}(0.51)$ & $1.88 \mathrm{Aa}^{\dagger}(0.24)$ & $1.44 \mathrm{Aa}^{\dagger}(0.12)$ & $2.13 \mathrm{Aa}^{\dagger}(0.34)$ \\
\hline $10-20$ & $1.84 \mathrm{Aa}^{\dagger}(0.24)$ & $1.37 \mathrm{Aa}^{\dagger}(0.30)$ & $1.79 \mathrm{Aa}^{\dagger}(0.35)$ & $1.92 \mathrm{Aa}^{\dagger}(0.20)$ & $1.77 \mathrm{Aa}^{\dagger}(0.23)$ & $1.93 \mathrm{Aa}^{\dagger}(0.30)$ & $1.58 \mathrm{Aa}^{\dagger}(0.30)$ \\
\hline $20-30$ & $1.91 \mathrm{Aa}^{\dagger}(0.43)$ & $1.68 \mathrm{Aa}^{\dagger}(0.19)$ & $1.48 \mathrm{Aa}^{\dagger}(0.33)$ & $1.62 \mathrm{Aa}^{\dagger}(0.26)$ & $1.75 \mathrm{Aa}^{\dagger}(0.32)$ & $1.62 \mathrm{Aa}^{\dagger}(0.16)$ & $2.00 \mathrm{Aa}^{\dagger}(0.27)$ \\
\hline $30-40$ & $1.69 \mathrm{Aa}^{\dagger}(0.33)$ & $1.80 \mathrm{Aa}^{\dagger}(0.25)$ & $1.28 \mathrm{Aa}^{\dagger}(0.18)$ & $1.30 \mathrm{Aa}^{\dagger}(0.30)$ & $1.76 \mathrm{Aa}^{\dagger}(0.26)$ & $1.24 \mathrm{Aa}^{\dagger}(0.09)$ & $1.69 \mathrm{Aa}^{\dagger}(0.40)$ \\
\hline
\end{tabular}

Table 2 - Humic substances evaluation indexes under seven weed control methods in four depths between coffee rows.

Weed control methods between coffee rows

\begin{tabular}{lcccccccc}
\hline Depth, cm & HAWE $^{1}$ & PMOW & HERB & GMAY & GMMA & SCAP & CONT \\
\hline \multicolumn{7}{c}{ Carbon linked to humic acid / carbon linked to fulvic acid - C-HA / C-FA } \\
$0-10$ & 1.43 & 1.16 & 1.38 & 1.56 & 1.32 & 1.81 & 1.27 \\
$10-20$ & 1.17 & 1.46 & 1.30 & 1.19 & 1.31 & 1.21 & 1.51 \\
$20-30$ & 1.18 & 1.16 & 1.42 & 1.34 & 0.99 & 1.40 & 1.26 \\
$30-40$ & 1.23 & 1.19 & 1.52 & 1.62 & 1.40 & 1.76 & 1.35 \\
\hline
\end{tabular}

Carbon linked to humic + fulvic acid / Carbon linked to humin -

$$
[(\mathrm{C}-\mathrm{HA}+\mathrm{C}-\mathrm{FA}) / \mathrm{C}-\mathrm{HU}]
$$

$\begin{array}{llllllll}0-10 & 1.16 & 1.04 & 1.18 & 0.91 & 1.12 & 0.73 & 0.93\end{array}$

$\begin{array}{llllllll}10-20 & 1.66 & 1.45 & 1.77 & 1.83 & 1.59 & 1.54 & 1.34\end{array}$

$\begin{array}{llllllll}20-30 & 1.85 & 1.67 & 1.78 & 1.74 & 1.52 & 1.66 & 1.76\end{array}$

$\begin{array}{llllllll}30-40 & 1.77 & 2.01 & 1.78 & 1.62 & 1.79 & 1.95 & 2.10\end{array}$

'HAWE: hand weeding; PMOW: portable mechanical mower; HERB: pre and post-emergence herbicides; GMAY: soil cover with green manure peanut horse (Arachis hypogeae); GMMA: soil cover with green manure dwarf mucuna; SCAP: no-weed control between coffee row; CONT: weed check.

layer $(0-10 \mathrm{~cm})$, for all weed control methods considered (cultural, biological and chemical).

Humin tends to accumulate in the topsoil due to its intrinsic characteristics and structural features (high stability with soil mineral matrix, recalcitrance, lack of mobility along the soil depth profile, insolubility in acidic and basic conditions) (Stevenson, 1994).
Among the cultural weed control group, SCAP and CONT had a $25 \%$ increase in C-HU in the topsoil (0$10 \mathrm{~cm})$, compared with GMMA and GMAY. The higher C-HU content observed may be attributed to the similarity in characteristics presented by SCAP and CONT (lack of soil disturbance and tillage activities at the inter-rows, and, thus, higher weed species diversity).

Plant residues that remained on the soil surface after the coffee tree pruning process may have been responsible for an increase in $\mathrm{C}-\mathrm{HU}$, since such residues present recalcitrant structures (lignin, cellulose and hemicelluloses), and are considered the main precursors of humified organic matter (Flaig, 1988).

For the mechanical weed control group, the use of portable mower (PMOW) led to a $9 \%$ increase in C-HU compared to hand weeding (HAWE). The use of the mechanical device chops and distributes plant residues, creating a mulch layer over the soil surface.

Thus, this mulch layer formed at the PMOW areas, together with the coffee crop pruning residue, may contain more resistant structures, and enhance the SOM humified fraction, leading to higher C-HU content in the topsoil.

The chemical weed method (HERB) showed an average decrease of $28 \%$ compared to the weed check (CONT) area. The use of herbicides as a weed control method limits the available plant material, interfering directly in the humification process, and consequently, in the incidence of HS and distribution, ultimately leading to a decrease in carbon content. 
Table $3-E_{4} / E_{6}$ ratio for humic and fulvic acids.

\begin{tabular}{|c|c|c|c|c|c|c|c|}
\hline \multicolumn{8}{|c|}{ Weed control methods between coffee rows } \\
\hline Depth, cm & HAWE $^{1}$ & PMOW & HERB & GMAY & GMMA & SCAP & CONT \\
\hline & \multicolumn{7}{|c|}{$\mathrm{E}_{4} / \mathrm{E}_{6}$ ratio Humic acid, a.u. ${ }^{2}$} \\
\hline $0-10$ & $9.41 \mathrm{Aa}(1.07)$ & $12.22 \mathrm{Aa}(2.25)$ & $9.26 \mathrm{Aa}(1.90)$ & $8.83 \mathrm{Aa}(2.88)$ & 4.18 Аa (1.82) & $9.42 \mathrm{Aa}(1.70)$ & $9.27 \mathrm{Aa}(1.72)$ \\
\hline $10-20$ & $7.53 \mathrm{Aa}(3.43)$ & $10.46 \mathrm{Aa}(2.54)$ & $11.92 \mathrm{Aa} \mathrm{(2.03)}$ & $6.34 \mathrm{Aa}(0.61)$ & $9.52 \mathrm{Aa}(1.92)$ & $6.25 \mathrm{Aa}(2.52)$ & $8.02 \mathrm{Aa}(1.39)$ \\
\hline $20-30$ & $8.60 \mathrm{Aa}(1.59)$ & $9.74 \mathrm{Aa}(2.51)$ & $10.21 \mathrm{Aa}(1.60)$ & $8.09 \mathrm{Aa}(1.74)$ & $10.17 \mathrm{Aa}(2.31)$ & $10.96 \mathrm{Aa}(1.45)$ & $8.05 \mathrm{Aa}(1.58)$ \\
\hline \multirow[t]{2}{*}{$30-40$} & $9.49 \mathrm{Aa}(2.15)$ & $9.14 \mathrm{Aa}(2.60)$ & $9.95 \mathrm{Aa}(2.04)$ & $8.15 \mathrm{Aa}(2.06)$ & $5.44 \mathrm{Aa}(1.05)$ & $8.79 \mathrm{Aa}(0.90)$ & $3.80 \mathrm{Aa}(0.80)$ \\
\hline & \multicolumn{7}{|c|}{$\mathrm{E}_{4} / \mathrm{E}_{6}$ ratio Fulvic acid, a.u. } \\
\hline $0-10$ & $10.40 \mathrm{Aa}(2.57)$ & $8.69 \mathrm{Aa}(2.43)$ & $6.52 \mathrm{Ab}(0.30)$ & $12.25 \mathrm{Aa}(0.63)$ & $6.72 \mathrm{Ab}(1.77)$ & $10.88 \mathrm{Aa}(2.00)$ & $9.95 \mathrm{Aa}(2.00)$ \\
\hline $10-20$ & 7.67 ABa (1.65) & 6.44 ABa (1.89) & $4.63 \mathrm{Aa}(0.13)$ & $5.13 \mathrm{Ba}(0.66)$ & $4.46 \mathrm{Aa}(0.21)$ & $5.88 \mathrm{Ba}(0.52)$ & $6.19 \mathrm{ABa}(0.98)$ \\
\hline $20-30$ & $5.94 \mathrm{ABa}(1.12)$ & $5.06 \mathrm{ABa}(0.70)$ & $5.08 \mathrm{Aa}(0.70)$ & $5.58 \mathrm{Ba}(0.82)$ & $6.03 \mathrm{Aa}(1.68)$ & 5.92 Ba (1.39) & $5.95 \mathrm{ABa}(1.39)$ \\
\hline $30-40$ & $5.00 \mathrm{Ba}(1.22)$ & $3.98 \mathrm{Ba}(0.19)$ & $5.00 \mathrm{Aa}(1.03)$ & 4.92 Ba (0.78) & $4.81 \mathrm{Aa}(0.69)$ & $3.21 \mathrm{Ba}(0.77)$ & $4.94 \mathrm{Ba}(1.36)$ \\
\hline
\end{tabular}

IHAWE: hand weeding; PMOW: portable mechanical mower; HERB: pre and post-emergence herbicides; GMAY: soil cover with green manure peanut horse (Arachis hypogeae); GMMA: soil cover with green manure dwarf mucuna; SCAP: no-weed control between coffee row; CONT: weed check. Upper case letters mean statistical analysis along depth increments within a given weed control/cover crop system. Lower case letters mean statistical analysis between weed control/cover crop at given depth increment layer (Tukey test, alpha $=0.05$ ); ${ }^{2}$ arbitrary units.

\section{Humic Substance Indexes}

Table 2 lists the C-HA/C-FA and the (C-HA+CFA)/ C-HU ratio. The C-HA/C-FA results for the analyzed samples, considering the entire set of weed control/cover crops studied, presented values between 0.99 and 1.81, and the highest variation (0.6) was observed in the SCAP samples. In the superficial layers, the cultural weed control method seems to have a higher impact rather than the other methods considered (chemical and mechanical).

In tropical areas, this ratio is generally lower than 1.0 due to lower soil exchangeable basis content, intense residue mineralization, climate and edaphic conditions, leading to alterations in the humification process (Canellas et al., 2002).

Thus, a possible positive ongoing status of the humification degree was observed for the trial experiment, particularly in areas subjected to cultural control, where it is believed to present higher nutrient and substrate availability.

The (C-HA + C-FA)/C-HU index presented values between 0.73 and 2.01. The highest values were observed when mechanical and chemical control methods at most of the depth increments were considered (0-10 $\mathrm{cm}$ to $20-30 \mathrm{~cm})$, whereas at $30-40 \mathrm{~cm}$ higher values were found for CONT and SCAP areas in the cultural control group.

Higher values for this index may be indicative of the movement of alkaline-soluble fractions along the soil profile and the incidence of organic carbon pools (Benites et al., 2005). This behavior can be attributed to the solubility characteristics of fulvic and humic fractions compared to humin.

Consequently, the results are consistent with the previous data which show carbon movement in the superficial layers for the mechanical (HAWE and PMOW) and chemical control group (HERB), and higher incidence of more stable carbon with depth increments for the cultural control group (CONT, SCAP, GMMA and GMAY).

\section{UV - Vis Spectroscopy}

Table 3 lists the $\mathrm{E}_{4} / \mathrm{E}_{6}$ ratio results for humic and fulvic acids. The weed control methods between coffee rows did not change the humic acid (HA) condensation degree. The $\mathrm{E}_{4} / \mathrm{E}_{6}$ ratio has been considered one of the main parameters for humification process assessment (Canellas et al., 2004).

SOM changes are usually not detectable in the short term (days and months), but over an extended period of time, such as years (Cerri et al., 2013). The humification process is slow and gradual and it can take a longer period (decades, centuries or even millennia) of processing in order to perceive significant structural changes in humic substances (Dores-Silva et al., 2015).

$\mathrm{E}_{4} / \mathrm{E}_{6}$ ratio data for fulvic acids showed an average decrease of $53 \%$ along depth increments for most of the field conditions considered. The behavior observed may be attributable to decreased microbial metabolic capacity in the topsoil, where fresh vegetal material accumulates in the superficial layers (González-Pérez et al., 2007), which slows the humification process, and ultimately, leads to incidence of less recalcitrant/aromatic structures.

Previous studies in the same experimental field showed higher accumulation of plant material from coffee tree pruning, cover crop residues and shoot mass in most of the weed control methods considered, as well as an increased degree of humification at depth (Martins et al., 2015).

Low $\mathrm{E}_{4} / \mathrm{E}_{6}$ ratios are considered to be indicative of the relatively higher degree of aromatization while high ratios indicate more aliphatic structures in the organic fractions (Chang et al., 2014).

Furthermore, higher values of the $\mathrm{E}_{4} / \mathrm{E}_{6}$ ratio may be indicative of oxygenated functional groups presence, such as hydroxyl, carbonyl, carboxyl, and ester groups (Dores-Silva et al., 2015; Enev et al., 2014).

The ratio is negatively related to $\mathrm{C}$ residence time in soil, and, therefore, the more recalcitrant and the lon- 
ger the HS turnover, the lower should be the $\mathrm{E}_{4} / \mathrm{E}_{6}$ ratio (Martin-Neto et al., 1998), and, consequently, the humic fraction should be more humified.

Thus, the behavior observed may be related to retarded humification process in the topsoil, and an enhanced aromatic structure conjugation/condensation degree at depth for the fulvic acid fraction, particularly for cultural (SCAP, CONT, and GMAY) and mechanical (PMOW and HAWE) weed control methods.

\section{Conclusions}

Humic substances comprised between $47 \%$ and $50 \%$ of soil organic carbon. Pruning residues left on the soil surface as green manure directly affect nutrient cycling along the depth profile and the humification process by input of available substrate and recalcitrant structures. The different cover crops and weed control methods analyzed did not alter humic and fulvic acid carbon content. Nevertheless, it may have increased the aromatic ring conjugation/condensation in fulvic acids at deeper layers.

\section{Acknowledgements}

The authors would like to thank the Coordination for the Improvement of Higher Level Personnel - CAPES / Post-Doctoral National Program (PNPD2013241940075010001P1) for a scholarship to the first author, and the Brazilian Consortium for Coffee Research for financial support provided.

\section{References}

Araujo-Junior, C.F.; Rodrigues, B.N.; Chaves, J.C.D.; Yada Junior, G.M. 2013. Soil physical quality and carbon stocks related to weed control and cover crops in a Brazilian Oxisol. p. 181205. In: Soloneski, S.; Larramendy, M., eds. Weed and pest control: conventional and new challenges. InTech, Rijeka, Croatia.

Balota, E.L.; Chaves, J.C.D. 2010. Enzymatic activity and mineralization of carbon and nitrogen in soil cultivated with coffee and green manures. Revista Brasileira de Ciência do Solo 34: 1573-1583.

Benites, V.M.; Madari, B.; Machado, P.L.O.A. 2003. Extraction and Quantitative Fractionation of Soil Humic Substances: A Low-Cost Simplified Procedure $=$ Extração e Fracionamento Quantitativo de Substâncias Húmicas do Solo: Um Procedimento Simplificado de Baixo Custo. Embrapa, Rio de Janeiro, RJ, Brazil (in Portuguese).

Benites, V.M.; Mendonça, E.S.; Schaefer, C.E.G.; Novotny, E.H.; Reis, E.L.; Ker, J.C. 2005. Properties of black soil humic acids from high altitude rocky complexes in Brazil. Geoderma 127: 104-113.

Bot, A.; Benites, J. 2005. The Importance of Soil Organic Matter: Key to Drought-Resistant Soil and Sustained Food and Production. FAO, Rome, Italy.
Canellas, L.P.; Velloso, A.C.X.; Rumjanek, V.M.; Guridi, F.; Olivares, F.L.; Santos, G.A.; Braz-Filho, R. 2002. Distribution of the humified fractions and characteristics of the humic acids of an Ultisol under cultivation of Eucalyptus and sugar cane. Terra 20: 371-381.

Canellas, L.P.; Espindola, J.A.A.; Rezende, C.E.; Camargo, P.B.; Zandonadi, D.B.; Rumjanek, V.M.; Guerra, J.G.M.; Teixeira, G.M.; Braz-Filho, R. 2004. Organic matter quality in a soil cultivated with perennial herbaceous legumes. Scientia Agricola 61: 53-61.

Canellas, L.P.; Busato, J.G.; Dobbss, L.B.; Baldotto, M.A.; Rumjanek, V.M.; Olivares, F.L. 2010. Soil organic matter and nutrient pools under long-term non-burning management of sugar cane. European Journal of Soil Science 61: 375-383.

Cardoso, E.J.B.N.; Vasconcellos, R.L.F.; Bini, D.; Miyauchi, M.Y.H.; Santos, C.A.; Alves, P.R.L.; Paula, A.M.; Nakatani, A.S.; Pereira, J.M.; Nogueira, M.A. 2013. Soil health: looking for suitable indicators: what should be considered to assess the effects of use and management on soil health? Scientia Agricola 70: $274-289$.

Castro Filho, C.; Logan, T.J. 1991. Liming effects on the stability and erodibility of some Brazilian Oxisols. Soil Science Society of America Journal 55: 1407-1413.

Cerri, C.E.P.; Galdos, M.V.; Carvalho, J.L.N.; Feigl, B.J.; Cerri, C.C. 2013. Quantifying soil carbon stocks and greenhouse gas fluxes in the sugarcane agrosystem: point of view. Scientia Agricola 70: 361-368.

Chang, R.R.; Mylotte, R.; Hayes, M.H.B.; Mclerney, R.; Tzou, Y.M. 2014. A comparison of compositional differences between humic fractions isolated by the IHSS and exhaustive extraction procedures. Naturwissenschaften 101: 197-209.

Chen, Y.; Senesi, N.; Schnitzer, M. 1977. Information provided on humic substances by $\mathrm{E}_{4} / \mathrm{E}_{6}$ ratios. Soil Science Society of America Journal 41: 352-358.

Ding, G.; Novak, J.M.; Amarasiriwardena, D.; Hunt, P.G.; Xing, B. 2002. Soil organic matter characteristics as affected by tillage management. Soil Science Society of America Journal 66: 421429.

Dores-Silva, P.R.; Landgraf, M.D.; Rezende, M.O.O. 2015. Chemical differentiation of domestic sewage sludge and cattle manure stabilized by microbioreators: study by pyrolysis coupled to gas chromatography coupled to mass spectroscopy Journal of Brazilian Chemical Society 26: 860-868.

Enev, V.; Pospisílová, L.; Klucáková, M.; Liptaj, T.; Doskocil, L. 2014. Spectral characterization of selected humic substances. Soil and Water Research 9: 9-17.

Flaig, W. 1988. Generation of model chemical precursors. p. 7592. In: Frimmel, F.H.; Christman, F., eds. Humic substances and their role in the environment. John Wiley, New York, NY, USA.

Fuentes, M.; González-Gaitano, G.; García-Mina, J.M. 2006. The usefulness of UV-visible and fluorescence spectroscopies to study the chemical nature of humic substances from soils and composts. Organic Geochemistry 37: 1949-1959.

González-Pérez, M.; Milori, D.M.B.P.; Colnago, L.A.; Martin-Neto, L.; Melo, W.J. 2007. A laser-induced fluorescence spectroscopic study of organic matter in a Brazilian Oxisol under different tillage systems. Geoderma 138: 20-24. 
Helal, A.A.; Murad, G.A.; Helal, A.A. 2011. Characterization of different humic materials by various analytical techniques. Arabian Journal of Chemistry 4: 51-54.

Martín, A.; Díaz-Raviña, M.; Carballas, T. 2009. Evolution of composition and content of soil carbohydrates following forest wildfires. Biology and Fertility of Soils 45: 511-520.

Martin-Neto, L.; Rosell, R.; Sposito, G. 1998. Correlations of spectroscopic indicators of humification with mean annual rainfall along a temperate grassland climosequence. Geoderma 81: 305-311.

Martins, B.H.; Araujo-Junior, C.F.; Miyazawa, M.; Vieira, K.M.; Milori, D.M.B.P. 2015. Soil organic matter quality and weed diversity in coffee plantation area submitted to weed control and cover crops management. Soil and Tillage Research 153: 169-174.

Pavan, M.A.; Bloch, M.F.; Zempulski, H.D.; Miyazawa, M.; Zocoler, D.C. 1992. Manual of Soil Chemistry Analysis and Quality Control = Manual de Análise Química do Solo e Controle de Qualidade. IAPAR, Londrina, PR, Brazil (in Portuguese).

Pavan, M.A.; Chaves, J.C.D.; Siqueira, R.; Filho, A.A.; Filho, A.C.; Balota, E.L. 1999. High coffee population density to improve fertility of an Oxisol. Pesquisa Agropecuária Brasileira 34: 459465.

Ratnayake, R.R.; Seneviratne, G.; Kulasooriya, S.A. 2013. Effect of soil carbohydrates on nutrient availability in natural forests and cultivated lands in Sri-Lanka. European Journal of Soil Science 46: 579-586.
Santos, L.M.; Simões, M.L.; Melo, W.J.; Martin-Neto, L.; PereiraFilho, E.R. 2010. Application of chemometrics methods in the evaluation of chemical and spectroscopic data on organic matter in Oxisols from sewage sludge applications. Geoderma 155: 121-127.

Schulte, E.E.; Hoskins, B. 2011. Recommended soil organic matter tests. p. 47-56. In: Horton, M.L., ed. Recommended soil testing procedures for the Northeastern United States. University of Delaware, Newark, DE, USA. (Northeastern Regional Bulletin, 493).

Song, X.; Liu, S.; Liu, Q.; Zhang, W.; Hu, C. 2014. Carbon sequestration in soil humic substances under long-term fertilization in a wheat-maize system from North China. Journal of Integrative Agriculture 13: 562-569.

Stevenson, F.J. 1994. Humus Chemistry: Genesis, Composition, Reactions. John Wiley, New York, NY, USA.

Walkley, A.; Black, I. 1934. An examination of the Degtjareff method for determining soil organic matter, and a proposed modification of the chromic acid titration method. Soil Science 37: 29-38.

Zhang, X.; Wang, K.; Ervin, E.H. 2010. Optimizing dosages of seaweed extract-based cytokinins and zeatin bioside for improving creeping bentgrass heat tolerance. Crop Science 50: 316-320. 